\title{
High-Intensity Single Bunch Instability Behavior In The New SLC Damping Ring Vacuum Chamber*
}

\author{
K. Bane, J. Bowers, A. Chao, T. Chen, F. J. Decker, R. L. Holtzapple, P. Krejcik, T. Limberg, A. Lisin, \\ B. McKee, M. G. Minty, C.-K. Ng, M. Pietryka, B. Podobedov, A. Rackelmann, C. Rago, \\ T. Raubenheimer, M. C. Ross, R. H. Siemann, C. Simopoulos, W. Spence, J. Spencer, R. Stege, F. Tian, \\ J. Turner, J. Weinberg, D. Whittum, D. Wright, F. Zimmermann \\ Stanford Linear Accelerator Center, Stanford University, Stanford, CA 94309 USA
}

New low-impedance vacuum chambers were installed in the SLC damping rings for the 1994 run after finding a single bunch instability with the old chamber. Although the threshold is lower with the new vacuum chamber, the instability is less severe, and we are now routinely operating at intensities of $4.5 \times 10^{10}$ particles per bunch (ppb) compared to $3 \times 10^{10} \mathrm{ppb}$ in 1993 . The vacuum chamber upgrade is described, and measurements of the bunch length, energy spread, and frequency and time domain signatures of the instability are presented.

\section{VACUUM CHAMBER UPGRADE}

The old vacuum chamber is described in Ref. 1. Although there are resistive elements such as the RF cavities and complex, hard to characterize elements such as septa, the calculated impedance was predominantly inductive with the contributions of different elements given in Table 1.

Table 1. Vacuum Chamber Inductance $(\mathrm{nH})$

\begin{tabular}{|l|c|c|}
\hline \multicolumn{1}{|c|}{ Element } & $\begin{array}{c}\text { Old } \\
\text { Chamber }\end{array}$ & $\begin{array}{c}\text { New } \\
\text { Chamber* }\end{array}$ \\
\hline Synch. Radiation Masks & 9.5 & ---- \\
\hline Bellows & ---- & 1.1 \\
\hline $\begin{array}{l}\text { Quadrupole to Dipole } \\
\text { Chamber Transitions }\end{array}$ & 9.3 & 2.4 \\
\hline Ion Pump Slots & 0.2 & 0.05 \\
\hline Kicker Magnet Bellows & 4.1 & ---- \\
\hline Flex Joints & 3.6 & ---- \\
\hline Beam Position Monitors & 3.5 & 0.2 \\
\hline Other & 2.4 & 2.4 \\
\hline \multicolumn{1}{|c|}{ TOTAL } & 33 & 6 \\
\hline
\end{tabular}

$\dagger$ From ref 1. Bellows included in Table 1 of [1] were shielded in a previous upgrade. Changes to that table from recent calculations are included here.

* Many of the impedance calculations are in ref 2 .

The synchrotron radiation masks and flex joints were associated with chamber flexibility. The masks protected bellows at one end of each four-foot long chamber section, and the flex joints added flexibility to the middle of each section. Flexibility was needed to compensate for limited precision in the adjustment of magnet positions and variations in chamber geometry during fabrication. Part of the upgrade was installation of new magnet and vacuum chamber mounts capable of being surveyed and positioned to $\pm 100 \mu \mathrm{m}$. In addition, the chambers were assembled in eight foot sections in a precision fixture that positioned parts prior to welding and provided a jig for minor adjustments after welding. By using these techniques flex joints became unnecessary and the number of bellows could be reduced by a factor of two. Synchrotron radiation masking was incorporated into the bellows RF shield, so the net change in the inductance from bellows and flex joints was from 13.1 $\mathrm{nH}$ to $1.1 \mathrm{nH}$.

The vacuum chamber profile must be rectangular in the dipoles for maximum damping and circular in the quadrupoles for adequate aperture. Modern materials and machining techniques allowed these transitions to be made over $5 \mathrm{~cm}$ versus $6 \mathrm{~mm}$ in the old chamber. Glidcop ${ }^{3}$ was chosen for the combination of strength and thermal conductivity needed to conduct away heat from synchrotron radiation. The transition was made smoothly by electrodischarge machining a continuous change from a circular to a rectangular profile over the length of the transition.

Other changes were the redesign of the beam position monitors and the slots between the beam and distributed ion pump chambers. The beam position monitors were made at the same radius as the beam pipe itself instead of being recessed. The pump slots were made narrower and deeper to cut-off higher frequency fields, and several slots were used instead of one to maintain the pumping speed. The pump slot impedance is strongly frequency dependent, and this change is important even though it does not appear so in Table 1. Finally, the bellows at the ends of the ceramic beam pipes for the injection and extraction kicker magnets were shielded.

All of these changes were made to fit within the mechanical constraints of existing magnets and other beam line hardware.

\section{INSTABILITY PROPERTIES}

A damping ring instability limited the SLC beam to $3 \times 10^{10} \mathrm{ppb}$ with the old vacuum chamber. The characteristics of that instability were: i) threshold $\mathrm{I} \approx$ $3 \times 10^{10} \mathrm{ppb}$, ii) signals at about three times the synchrotron frequency, $\mathrm{f}_{\mathrm{S}}$, indicating a predominantly sextupole structure in phase space, and iii) transient behavior with the instability amplitude building up in several synchrotron periods and

* Work supported by the Department of Energy, contract DE-AC03-76SF00515. 
then relaxing with roughly the radiation damping time. ${ }^{4}$ Based on simulations it was expected that the threshold with the new vacuum chamber would be $5-6 \times 10^{10} \mathrm{ppb}$. However, the threshold was reduced to $1.5-2 \times 10^{10} \mathrm{ppb}$, but with the redeeming feature that the consequences for the SLC were less dramatic. Towards the end of the 1994 1995 run we were running with bunches of up to $4.5 \times 10^{10}$ $\mathrm{ppb}$ in the damping rings and colliding beams of up to $3.8 \times 10^{10} \mathrm{ppb}$. The SLC intensity limit was not due to the damping ring instability, and there was at best marginal evidence of a correlation between the instability and linac performance. Details of the instability follow.

The energy spread was measured with a wire scanner in a dispersive region of the extraction line. It should be constant below the instability threshold which based on the data in Fig. 1 is between 1.5 and $2.0 \times 10^{10} \mathrm{ppb}$ for an accelerating voltage $\mathrm{V}_{\mathrm{RF}}=945 \mathrm{kV}$.

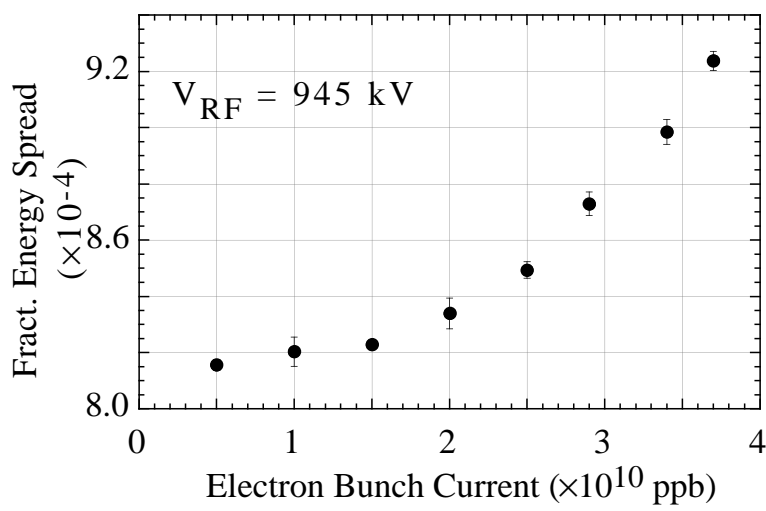

Figure 1: Energy spread as a function of current.

Bunch length was measured with a streak camera ${ }^{5}$ and a wire scanner in the extraction line following an accelerating section phased to produce a time-energy correlation. ${ }^{4}$ The distributions are not Gaussian, and the results in Fig. 2 are based on the FWHM. There is a small systematic offset between the wire scanner and streak camera data, but there is good agreement on the current dependence. Clearly there is a significant reduction in bunch lengthening with the new chamber.

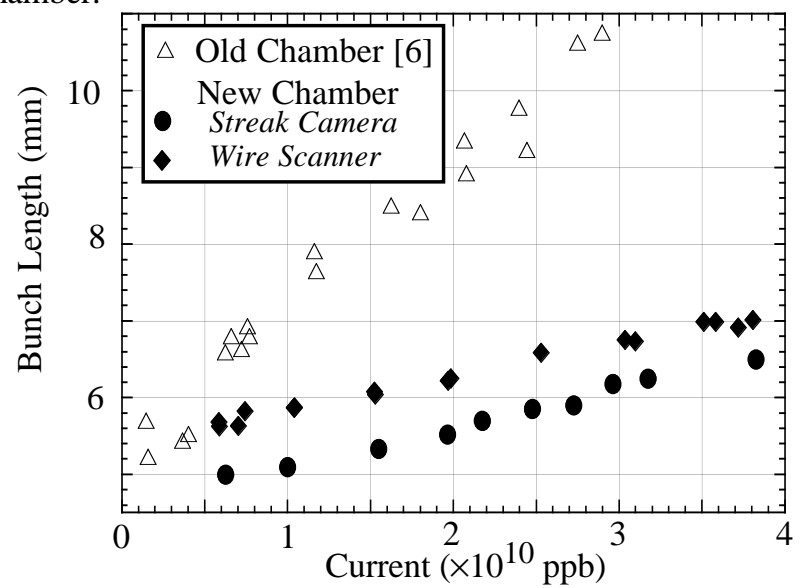

Figure 2: Bunch length dependence on current. Bunch lengths are $\mathrm{FWHM} / 2.35 . \mathrm{V}_{\mathrm{RF}}=800 \mathrm{kV}$.
A study was made of the image-by-image variation of the streak camera profile. The conclusion was that the bunch length varied less than $\pm 3 \%$ image-by-image. This variation and the differences in images were consistent with those expected from camera noise.

A third diagnostic was spectral analysis of a beam position monitor electrode. The spectrum analyzer was used in three different modes: i) as a swept frequency analyzer, ii) as a fixed frequency receiver, and iii) as a down converter input to a digital signal processing system. ${ }^{7}$ Figure 3 is a DSP output when the instability was present.

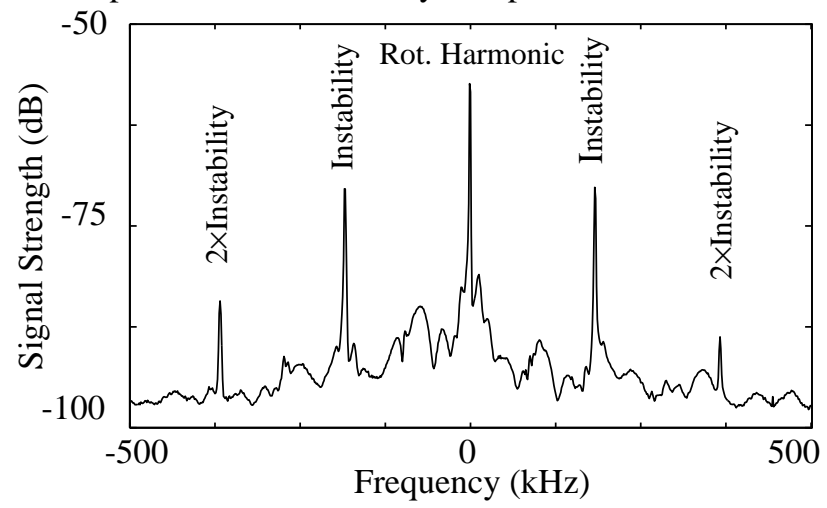

Figure 3: Spectrum centered around a rotation harmonic at $23 \mathrm{GHz}$. The current and synchrotron frequency at that time were $\mathrm{I}=2.9 \times 10^{10} \mathrm{ppb}$ and $\mathrm{f}_{\mathrm{S}}=104 \mathrm{kHz}$.

The sidebands associated with the instability are clearly visible. They are at $\mathrm{f}=184 \mathrm{kHz}=1.77 \mathrm{f}_{\mathrm{S}}$ from the rotation harmonic. This is the signature of a predominantly quadrupole mode in contrast to the sextupole mode with the old vacuum chamber. The frequency increases with decreasing current; the slope is $\mathrm{df} / \mathrm{dI} \sim-6 \mathrm{kHz} / 10^{10}$. This is opposite to the current dependence with the old chamber which had a slope $\mathrm{df} / \mathrm{dI} \sim 9 \mathrm{kHz} / 10^{10} .4$ The second harmonics in this spectrum are seen whenever the instability in strong. We have measured differences in the amplitudes of the positive and negative frequency sidebands also, and we have established that there are differences characteristic of the instability rather than being due to variation in beam position monitor sensitivity. Which sideband is stronger can depend on how far the current is above threshold.

Spectra have been taken under a number of conditions, and some conclusions can be reached from these data. First, there are no significant differences between the electron and positron damping rings. The impedances of these two rings are expected to be close, but there could be ion effects in the electron ring. We conclude that possible ion effects are not contributing to the instability.

Second, with two bunches the sidebands of adjacent rotation harmonics are roughly equal in amplitude while the rotation harmonics themselves display the alternating pattern expected with two bunches. We conclude from this that the instability is a single bunch instability.

The transient nature of the instability was studied by using the spectrum analyzer as a receiver set to a sideband 
frequency. Figure 4 is one example of the output. The transient at injection/extraction time is due to the kicker noise and phase space mismatch at injection. The instability signal rises out of the noise at about $3 \mathrm{~ms}$ and oscillates in amplitude by about $10 \mathrm{~dB}$ with rise and fall times in the range of 250 to $500 \mu \mathrm{s}$. This is a common pattern seen with both one and two bunches and is reminiscent of the "sawtooth" behavior we saw with the old vacuum chamber.

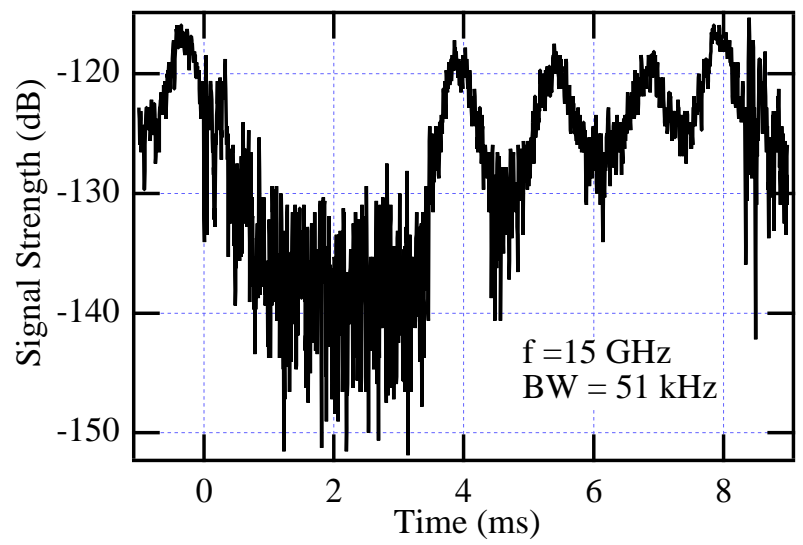

Figure 4: Video output of the spectrum analyzer tuned to a sideband frequency. The beam had two bunches, I = $3.5 \times 10^{10} \mathrm{ppb}$. Injection and extraction are at 0 and $8.3 \mathrm{~ms}$.

However, the sawtooth is not the only behavior that has been seen. Figure 5 shows a different set of conditions. The common feature of Figs. 4 and 5 is the appearance of the instability at roughly $3 \mathrm{~ms}$ into the store indicating that it takes about 2 damping times for the peak current to reach the critical value for instability.

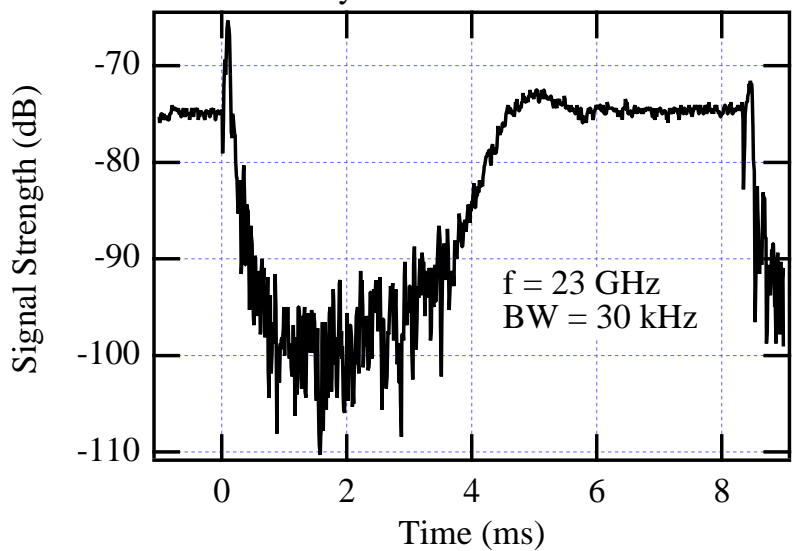

Figure 5: Video output for analyzer tuned to one of the sidebands. One bunch, $I=3.9 \times 10^{10} \mathrm{ppb}$. Injection and extraction are at 0 and $8.3 \mathrm{~ms}$.

We have studied the dependence of the threshold on a number of parameters, and, although our understanding is incomplete, there is clear evidence that the RF accelerating voltage is one of the key factors. Figure 6 is a graph of the signal amplitude just before extraction as a function of the accelerating voltage. There is no measurable signal below $800 \mathrm{kV}$, and the instability is present on every pulse at 865 $\mathrm{kV}\left(\mathrm{V}_{\mathrm{RF}}=865 \mathrm{kV}\right.$ in Fig. 5). In between the amplitude of the instability is not constant, and whether it is present on a given pulse depends on the phase of the transient at extraction time.

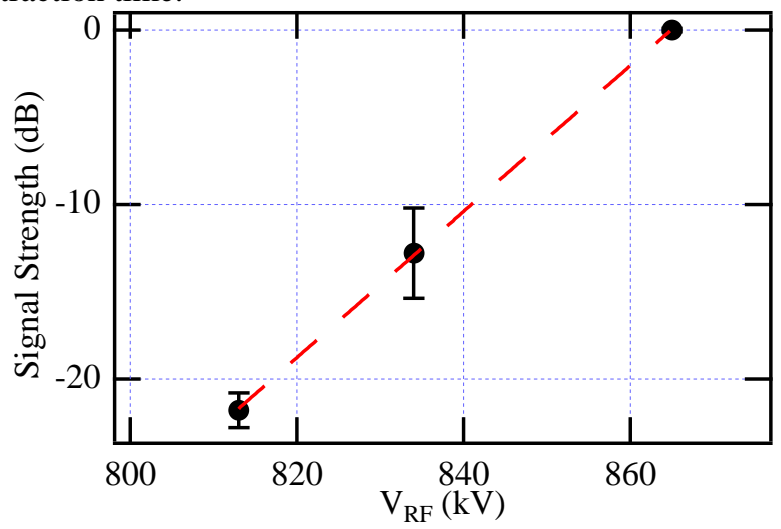

Figure 6: Instability signal amplitude $50 \mu$ s before extraction. The beam had 1 bunch of $\mathrm{I}=3.9 \times 10^{10} \mathrm{ppb}$. Noise level $-25 \mathrm{db}$. Error bars show RMS signal variation.

\section{SUMMARY AND CONCLUSIONS}

We have described the changes in the damping ring impedance and the observations of instability with the new vacuum chamber. Some of the results with the old chamber 4 and some preliminary results with the new one have been or could be interpreted with the ideas in a number of theoretical and simulation papers. ${ }^{8-13}$ We look forward to quantitative comparisons with the data in this paper.

Finally, we are relieved that we could increase the SLC current despite this unexpected instability.

\section{ACKNOWLEDGEMENTS}

The upgrade we described would not have been successful without the high quality, dedicated work of the SLAC machinists, surveyors, vacuum technicians, and mechanical technicians. They have our sincere thanks.

\section{REFERENCES}

1. Karl L. F. Bane, Proc 1988 EPAC, 637 (1988).

2. K. Bane \& C. Ng, Proc 1993 PAC, 3432 (1993).

3. SCM Metal Products.

4. P. Krejcik et al, Proc 1993 PAC, 3240 (1993).

5. R. L. Holtzapple et al, WXE05, 1995 PAC.

6. L. Rivkin et al, Proc 1988 EPAC, 634 (1988).

7. R. Stege et al, 1992 Accel Inst Workshop, 217 (1992).

8. X. T. Yu \& J. S. Wurtele, Proc1993 PAC, 3327 (1993).

9. K. Oide, KEK-preprint-94-138 (Nov, 1994).

10. R. Baartman, M. D'Yachkov, WAC20, 1995 PAC.

11. K. L. F. Bane, K. Oide, WAC16, 1995 PAC.

12. A. Chao et al, WAB10, 1995 PAC.

13. B. Chen, WAC31, 1995 PAC. 